\title{
Quantidade de gordura no músculo levantador da pálpebra de portadores de ptose congênita
}

\author{
Congenital ptosis associated with fatty infiltration oflevator eyelid muscle
}

\author{
Cristiano Pinheiro Leite ${ }^{1}$ \\ Silvana Artioli Schellini ${ }^{2}$ \\ Cláudia Helena Pellizzon ${ }^{3}$ \\ Mariângela Esther Alencar Marques ${ }^{4}$ \\ Carlos Roberto Padovani ${ }^{5}$
}

\begin{tabular}{|l|}
\hline RESUMO \\
\hline Objetivo: Quantificara gordura presente no músculolevantador da pálpebra \\
de portadores de ptose congênita, correlacionando este achado com \\
fatores clínico-epidemiológicos desta afecção. Métodos: Vinte e duas \\
amostras de músculo levantador da pálpebra superior, provenientes de \\
portadores de ptose congênita, foram avaliadas morfometricamente, com \\
o intuito de quantificar a gordura presente nos espécimes e correlacionar \\
este achado com características como idade, sexo, grau de ptose e função \\
do músculo levantador. Resultados: Não houve correlação entre a quanti- \\
dade de gordura encontrada no músculo levantador de portadores de \\
ptose congênita e os dados clínicos dos pacientes estudados. Conclusão: \\
A quantidade de gordura presente no músculo levantador da pálpebra \\
superior, nas condições do presente estudo, não está associada com \\
idade, sexo, grau de ptose ou função do músculo levantador. Novos \\
estudos serão necessários para avaliar a real alteração que ocorre no \\
músculo levantador da pálpebra de indivíduos com ptose palpebral. \\
\hline
\end{tabular}

Descritores: Blefaroptose/congênito; Befaroptose/epidemiologia; Pálpebras/patologia; Músculos oculomotores/patologia; Análise quantitativa

\section{INTRODUCূ̃̃̃O}

A blefaroptose congênita é uma condição uni ou bilateral, na qual existe queda da pálpebra superior. Ocorre geralmente como um defeito isolado, em crianças sadias, embora possa estar associada a outras anormalidades. Em geral, é uma condição idiopática, persistente, descoberta logo após o nascimento. Na maioria dos casos apresenta-se como um quadro não progressivo, sem causa identificável, com sinais e sintomas aparentemente confinados à pálpebra superior ${ }^{(1)}$.

Dentre os tipos de ptose, o grupo composto pelas ptoses congênitas é um dos mais importantes, não só pela alta freqüência, uma vez que compreendem $50 \%$ de todos os casos de ptose, como também pelo caráter ambliopigênico desta afecção, decorrente do obscurecimento do eixo visual, provocado pelo abaixamento da margem palpebral ${ }^{(2)}$.

Há diminuição da abertura palpebral, com redução da distância entre a margem palpebral superior e o reflexo corneal na posição primária do olhar (MRD), além da diminuição da excursão do músculo levantador da pálpebra superior (MEPS). A função do músculo levantador geralmente está relacionada com o grau de ptose, e sua função pobre ou ausente é refletida pela ausência da prega palpebral superior ${ }^{(3)}$.

O tratamento da ptose congênita é eminentemente cirúrgico. Dentre as técnicas cirúrgicas, a ressecção do MEPS permanece, na maioria dos casos, como primeira opção. A quantidade de ressecção é determinada pela função 
do músculo levantador e pela gravidade da ptose. O objetivo da cirurgia envolve, não somente a prevenção da ambliopia, como também o efeito cosmético ${ }^{(4)}$.

A patogênese da ptose congênita permanece controversa. Alguns defendem tratar-se de uma disgenesia, onde haveria um defeito no desenvolvimento do músculo; outros preferem classificar o processo como uma distrofia, que representaria um processo herdado, caracterizado por fraqueza e emaciação do músculo ${ }^{(4)}$. Achados histológicos como perda das estriações, diminuição do diâmetro das fibras musculares, retração do sarcolema, alinhamento dos núcleos, degeneração fibrosa e gordurosa da fibra muscular falam a favor de distrofia ${ }^{(5)}$. A disfunção muscular parece estar associada ao achado de infiltração lipídica no músculo levantador ${ }^{(6)}$, porém, faltam estudos que comprovem esta associação.

O objetivo deste estudo é quantificar a gordura presente no músculo levantador de indivíduos com ptose congênita, correlacionando este achado com fatores clínico-epidemiológicos dos portadores.

\section{MÉTODOS}

Foram incluídos neste estudo portadores de ptose congênita submetidos à ressecção do músculo levantador da pálpebra superior, no Hospital das Clínicas da UNESP - Botucatu, entre dezembro de 1998 a fevereiro de 2004. Os pacientes foram selecionados, retrospectivamente, através do banco de dados do Serviço de Patologia deste hospital. Os dados relativos ao histórico dos pacientes (sexo, idade, grau de ptose e função do músculo levantador) foram obtidos por meio da revisão do prontuário médico. A ptose foi classificada em leve, quando a MRD era de 2 milímetros, moderada quando a medida era igual a 1 milímetro e grave, quando os valores eram iguais a zero ou negativos. A função do músculo levantador foi classificada como boa, quando o paciente apresentava excursão da pálpebra superior igual ou acima de 10 milímetros, ou fraca, quando apresentava excursão menor ou igual a 5 milímetros.

Os espécimes cirúrgicos, obtidos quando da cirurgia para correção da ptose por ressecção do músculo levantador, foram preservados em formaldeído $10 \%$, embebidos em parafina, seccionados em cortes de $5 \mu \mathrm{m}$ e corados por HematoxilinaEosina.

Foi realizado exame morfométrico, após digitalização fotográfica dos espécimes, pelo software Leica Q.Win, através do módulo semi-automático. Usando este programa, foram mensuradas as alturas das áreas ocupadas pela gordura dentro do espécime, fornecendo valores que posteriormente foram agrupados em tabela Excell e avaliados estatisticamente usando-se o teste não-paramétrico de Mann-Whitney, para correlacionar a quantidade de gordura com as variáveis qualitativas, e o coeficiente de correlação de Spearman, para verificar associação com a idade. O nível de rejeição para hipótese de nulidade foi fixado em menor que $5 \%(p<0,05)$.

\section{RESULTADOS}

Vinte e dois espécimes anátomo-patológicos de músculo levantador, provenientes de 22 pacientes submetidos à correção cirúrgica da ptose por meio da ressecção do MEPS, com diagnóstico clínico de ptose congênita, foram analisados através de estudo morfométrico, interessando quantificar a gordura presente no material.

Dos 22 pacientes, 14 eram do sexo masculino e 8 do sexo feminino, com idades variando entre 4 meses a 25 anos. Onze casos foram clinicamente classificados como tendo ptose moderada, e outros 11, como tendo ptose grave. Não havia nenhum caso de ptose leve dentre os pacientes estudados. Apenas 2 pacientes foram classificados como tendo uma função boa do MEPS, enquanto 20, tinham função fraca.

A tabela 1 correlaciona a quantidade de gordura encontrada no estudo histológico com o sexo, não tendo sido encontrada diferença estatisticamente significativa com relação a este parâmetro de estudo $(\mathrm{p}>0,05)$. Em relação à idade, foi encontrado um coeficiente de correlação de 0,14 (p>0,05), não demonstrando associação entre as variáveis.

A tabela 2 mostra a relação entre o grau de ptose e a quantidade de gordura. Não foi demonstrada associação entre as variáveis.

A relação entre a quantidade de gordura e a função do músculo levantador é demonstrada na tabela 3. Mais uma vez, não se verificou associação entre as variáveis.

\section{DISCUSSÃO}

Apesar da infiltração gordurosa em músculos levantadores ser um achado clínico constantemente observado em por-

\begin{tabular}{|ccc|}
\hline $\begin{array}{c}\text { Tabela 1. Mediana e semi-amplitude total da gordura em função } \\
\text { do sexo }\end{array}$ \\
$\begin{array}{c}\text { Masculino } \\
(\mathbf{n}=14)\end{array}$ & $\begin{array}{c}\text { Feminino } \\
(\mathbf{n}=8)\end{array}$ & $\begin{array}{c}\text { Resultado do } \\
\text { teste estatístico }\end{array}$ \\
$801,24 \pm 777,98$ & $941,45 \pm 542,27$ & $0,55(p>0,05)$ \\
\hline
\end{tabular}

\begin{tabular}{|ccc|}
\hline \multicolumn{2}{|c|}{ Tabela 2. Mediana e semi-amplitude total da quantidade de gordura } \\
em função do grau de ptose
\end{tabular}

\begin{tabular}{|c|cc|}
\hline $\begin{array}{c}\text { Tabela 3. Mediana e semi-amplitude total da quantidade de gordura } \\
\text { em função da função do músculo levantador }\end{array}$ \\
$\begin{array}{c}\text { Masculino } \\
(\mathbf{n}=14)\end{array}$ & $\begin{array}{c}\text { Feminino } \\
(\mathbf{n}=8)\end{array}$ & $\begin{array}{c}\text { Resultado do } \\
\text { teste estatístico }\end{array}$ \\
$875,54 \pm 663,42$ & $934,00 \pm 668,80$ & $0,11(p>0,05)$ \\
\hline
\end{tabular}


tadores de ptose palpebral (observação pessoal), no presente estudo não se confirmou que a quantidade de gordura presente nos espécimes de MEPS, provenientes de ptoses congênitas, tenha correlação positiva com idade, sexo, grau de ptose e função do músculo levantador.

A ptose congênita é uma condição bastante conhecida clinicamente. Entretanto, sua patogênese ainda é controversa, podendo resultar de um defeito primário do MEPS, como uma miopatia, que pode ter surgido de uma disgenesia do complexo do levantador, ou de fibrose, com diminuição da quantidade de fibras, como se a doença representasse uma forma localizada de distrofia muscular ${ }^{(3-5)}$.

A ptose congênita pode também ser considerada uma desordem do desenvolvimento, em virtude da ausência de achados histológicos confiáveis que caracterizassem distrofia ${ }^{(3)}$.

Assim, três seriam as razões principais para a dificuldade em classificar a patogênese da ptose congênita: 1) a representatividade das amostras histológicas obtidas da ressecção cirúrgica é insuficiente, uma vez que demonstram parte do MEPS, e não o músculo como um todo; 2) o desenvolvimento normal do músculo levantador ainda é desconhecido, em função da falta de estudos embriológicos e fetais; 3) o sistema de classificação por si só é inapropriado, uma vez que utiliza uma classificação baseada em músculos esqueléticos. Destaca-se, ainda, o fato de muitos dos achados distróficos, na verdade, decorrerem de artefatos da preparação do material. A evidência contra a hipótese distrófica seria o fato das distrofias musculares estarem associadas ao caráter hereditário, fato este pouco associado a ptose congênita ${ }^{(3)}$.

Estudando 20 portadores de ptose involucional, observaram-se deiscência da porção média do ligamento de Whitnall, deslocamento lateral da placa tarsal da pálpebra superior e degeneração gordurosa do músculo levantador da pálpebra superior, na área do ligamento de Whitnall ${ }^{(6)}$. Outros também encontraram degeneração gordurosa no músculo levantador em $10 \%$ dos casos de ptose involucional ${ }^{(7)}$ e no músculo de Müller e levantador de 9 dos 115 portadores de ptose congênita ou adquirida ${ }^{(8)}$.

Apesar de não se ter encontrado no presente estudo correlação entre o grau de ptose e a quantidade de gordura presente no músculo levantador da pálpebra, esta observação pode ter ocorrido devido ao fato de que a área de ressecção está sempre próxima do local onde existe menor quantidade de músculo e maior quantidade de aponeurose muscular, ou seja, a área mais próxima da placa tarsal.

Também não foram utilizadas preparações especiais para avaliação da gordura e, no preparo do material, parte da gordura pode ter sido perdida pelo processo de inclusão que é feito em altas temperaturas, usando Xilol como solvente. Desta forma, características específicas do músculo levantador se- riam mais bem avaliadas usando outros métodos de microscopia óptica e também avaliações em microscopia eletrônica.

\section{CONCLUSÃO}

A quantidade de gordura presente em espécimes de músculo levantador da pálpebra superior de indivíduos com ptose congênita, nas condições do estudo, não está associada com idade, sexo, grau de ptose ou função do músculo levantador. Novos estudos são necessários para avaliar a real alteração que ocorre no músculo levantador da pálpebra de indivíduos com ptose palpebral.

\section{ABSTRACT}

Purpose: To quantify the fat in the levator muscle of patients with congenital ptosis, as related to clinical and epidemiological aspects of this disease. Methods: Twenty-two levator muscle samples of the superior eyelid from patients with congenital ptosis were morphometrically evaluated with aim of establishing a relationship between the fat quantity and age, sex, ptosis degree and levator muscle function. Results: According to our results the fat in the levator muscle of patients with congenital ptosis is not related to gender or epidemiologic aspects. Conclusion: Fat amount in the levator muscle from congenital ptosis is not related to age, sex, ptosis degree or levator muscle function. Other studies will be necessary to show the real alterations in the levator muscle related to eyelid ptosis.

Keywords: Blepharoptosis/congenital; Blepharoptosis/epidemiology; Eyelids/pathology; Oculomotor muscles/pathology; Quantitative analysis

\section{REFERÊNCIAS}

1. Clark BJ, Kemp EG, Behan WM, Lee WR. Abnormal extracellular material in the levator palpebrae superioris complex in congenital ptosis. Arch Ophthalmol. 1995;113(11):1414-9.

2. Cruz AAV. Blefaroptoses e retrações palpebrais. 5a ed. Rio de Janeiro: Cultura Médica, 1998

3. Baldwin HC, Manners RM. Congenital blepharoptosis: a literature review of the histology of levator palpebrae superioris muscle. Ophthal Plast Reconstr Surg. 2002;18(4):301-7.

4. Spaeth EB. An analysis of the causes, types, and factors important to the correction of congenital blepharoptosis. Am J Ophthalmol. 1971;71(3):696-717.

5. Sutula FC. Histological changes in congenital and acquired blepharoptosis. Eye. 1988;2(Pt 2):179-84.

6. Shore JW, McCord CD Jr. Anatomic changes in involutional blepharoptosis. Am J Ophthalmol. 1984;98(1):21-7.

7. Collin JR. Involutional ptosis. Aust N Z J Ophthalmol. 1986;14(2):109-12.

8. Cahill KV, Buerger GF Jr, Johnson BL. Ptosis associated with fatty infiltration of Muller's muscle and levator muscle. Ophthal Plast Reconstr Surg. 1986; 2(4):213-7. 